\title{
Does theory translate into practice? An observational study of current mathematics pedagogies in play-based kindergarten
}

Hanna Wickstrom, ${ }^{a}$ Angela Pyle ${ }^{a}, \&$ Christopher DeLuca ${ }^{b}$

a Ontario Institute for the Study of Education, University of Toronto, Canada

${ }^{\mathrm{b}}$ Faculty of Education, Queen's University, Kingston, Canada

Full Citation:

Wickstrom, H., Pyle, A., \& DeLuca, C. (2019). Does theory translate into practice? An observational study of current mathematics pedagogies in play-based kindergarten. Early Childhood Education Journal, 47(3), 287-295.

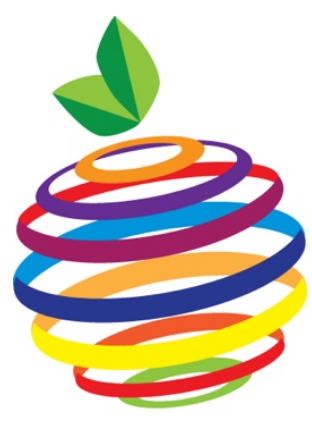

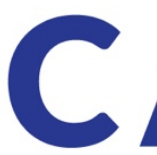

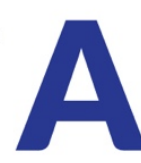

Classroom Research Team cdeluca.com
Contact:

Christopher DeLuca cdeluca@queensu.ca

@ChrisDeLuca20 
There is growing interest in improving mathematics education in kindergarten. This interest in early math, in part stems from declining scores on standardized testing (Stokke, 2015). While research describes the importance of early mathematical mastery for future success (Duncan et al., 2007; Presser, Ginsburg, \& Ertle, 2015), there is a lack of agreement on the best pedagogy to support early math learning. Some scholars argue that direct instruction best supports math learning (Doabler \& Fien, 2013) while others advocate for play-based pedagogies (Ginsburg, 2006). However, little empirical evidence documents exactly how teachers are supporting math education in the early years. Therefore, a fundamental step towards improving math education is to first understand the current implementation of math pedagogies in kindergarten. As such, the present study seeks to understand the extent to which teachers are integrating play and direct instruction to support children's mathematics learning.

\section{Play in Kindergarten Education}

Adults have used various criteria for perceiving and categorizing children's play (Turnbull \& Jenvey, 2006). Parten (1933) took a developmental perspective and classified play based upon the degree of social engagement and use of play materials which followed discrete developmental stages. Piaget (1951) classified play by stages of cognitive development; proposing that play has a developmental sequence. Pellegrini and Smith (1998) identified play based on behaviour and classified play into pretend/fantasy play, also described in the literature as sociodramatic play, and activity/locomotor play. Most recently, Pyle and Danniels (2017), presented play as a continuum, categorized by locus of control, ranging from child-directed, to mutually-directed, to teacher-directed play. Free, child-directed play is entirely controlled by the child, as they engage in spontaneous and fluid play, which is often pretend or sociodramatic in nature (Wallerstedt \& Pramling, 2012). Guided play is a mutually-directed collaborative 
experience between the teacher and child, as control over the play is shared, yet the extent to which each participant controls the play can vary. Teacher-directed play is controlled by the teacher, as they facilitate play scenarios that have predetermined outcomes (Gmitrová, Podhajecká, \& Gmitrov, 2009). These instances of play are highly structured, and often follow a rigid set of rules (Gmitrová et al., 2009). The present study takes an educational perspective, viewing play as pedagogy, and will therefore adhere to the categorization and definitions of play, outlined by this play continuum.

Pedagogically, the purpose of play is to support children's learning. Including children's developmental learning, such as socio-emotional skills (Tal, Fares, Azmi, \& Wabb, 2008) and academic learning, such as mathematics (Ginsburg, 2006). Within the academic domain of mathematics, play has been shown to support children's overall mathematical ideas, skills, and reasoning (Griffin 2004). Specifically, play supports children's counting and comparison ability (Kamii \& Housman 2000), spatial reasoning (Sarama \& Clements, 2009), and geometric knowledge (Fisher, Hirsh-Pasek, Newcombe, \& Golinkoff, 2013). Despite the many benefits of play, variability in implementation, based upon teachers' conceptualizations of play (Chrossen, Church, \& Tayler, 2016) may impact the outcome of play as pedagogy (Pyle, Poliszczuck, \& Danniels, 2018). In response to many of these limitations, researchers and educators alike consider direct instruction as a systematic and intentional alternative pedagogy.

\section{Direct Instruction}

Direct instruction is a teacher-controlled pedagogy whereby discrete concepts are broken down into smaller units that are deliberately sequenced and explicitly taught (Engelmann, Becker, Carnine, \& Rhine, 1981). Advocates of direct instruction espouse its suitability for supporting children who are at risk of developing math difficulties (Doabler \& Fien, 2013). 
Despite the benefits, direct instruction has also been described as a double-edged sword (Gopnik, 2012). Evidence suggests that when compared to children in playful-learning classrooms, children enrolled in programs with direct instruction display more inattention and stress behaviours (Hart et al., 1998). Another common critique is that direct instruction limits a child's self-efficacy, as the teacher controls the activity, thereby preventing the child from making decisions that direct their learning (Weisberg, Hirsh-Pasek, \& Golinkoff, 2013). Furthermore, direct instruction can limit children's problem-solving skills and exploration when introduced to novel stimuli, suggesting that children who learn through direct instruction often use a single approach to problem solving; the approach modeled by the instructor (Bonawitz, et al., 2011).

\section{Comparing Pedagogies}

To compare these pedagogies, we can turn to the work of Alfieri, Brooks, Aldrich, and Tenenbaum (2011) who conducted meta-analyses that analyzed explicit instruction, unassisteddiscovery (a child-directed approach to learning, similar to free play) and enhanced/assisted discovery (a shared-control approach to learning, similar to guided play). In regard to math learning, they concluded that explicit instruction was superior to unassisted discovery, but enhanced-discovery (i.e. guided play) led to greater student learning than both unassisted discovery and explicit instruction. This finding was corroborated by Fisher et al. (2013), who conducted an experimental study to determine the impact of pedagogy on children's geometric knowledge. Findings demonstrated that children's acquisition of geometric knowledge was impacted by instruction, as children who were taught through guided play performed significantly better than children in both the free play and direct instruction conditions.

The literature outlines a strong theoretical basis, empirically tested through rigorous experimental design, to understand how pedagogy impacts young children's acquisition of 
mathematical skill (Alfieri et al., 2011; Fisher et al., 2013). This knowledge is essential, yet incomplete, as research has yet to understand how these theoretical and experimental findings translate to classrooms. As such, this study fills a void in the literature by exploring the extent to which theory has translated into practice, with regards to mathematics pedagogy in kindergarten.

\section{Methods}

To understand the various pedagogies used to teach mathematics in kindergarten, this study conducted extensive classroom observations in Ontario, Canada. Ontario is an ideal setting in which to conduct this research as this province has recently introduced a new kindergarten program that mandates play as the primary pedagogy for reaching both academic and developmental standards (OME, 2016). Additionally, the Ontario kindergarten curriculum emphasizes the expectation that children achieve mastery of seven overall math standards including an understanding of numbers, concepts of measurement, classification of data, patterning, and mathematical operations (OME, 2016).

\section{Participants}

Twenty teachers from two public school districts and one independent school were recruited to participate in this study based on geographic location and willingness to participate. Teachers were recruited from a variety of demographic educational contexts (e.g. urban/rural, SES), teaching experiences, and were located in both public and alternative school settings. Upon ethical clearance from the universities, school boards, and independent schools, 20 teachers provided consent to collect observational data in their classrooms. Participants varied in their years of practice (range $=3-28$ years) and assignments (years teaching kindergarten ranged from 1-14 years). All, but one teacher, were female. Written parental consent was given for children to participate in the study and to appear in video recordings. 


\section{Data Collection}

Four to 10 hours of observational data were collected within each classroom, with a total of 140 hours of data collected. Videos, photographs and field notes were used to record observations. Using a running record observation protocol (Patton, 2014), observations focused on instructional periods, including both teacher-directed whole group activities (e.g. circle time, explicit lesson) and play-based activities (e.g. predetermined play centers and spontaneous play).

\section{Data Analysis}

Observational data, including field notes, photographs, and videos, were deductively analyzed on a class-by-class basis to develop single case descriptions (Patton, 2014). Within each class, instances of mathematics teaching and learning were identified. Guided by the literature, each instance of math was coded in regard to (a) orientation of activity: play (Fisher et al., 2013) or teacher-directed instruction (Engelmann et al., 1981) and (b) control over learning context: child, shared, or teacher-controlled (Pyle \& Danniels, 2017). From this coding, four distinct categories of pedagogy emerged (i.e., free play, guided play, teacher directed play, and direct instruction). These four pedagogies where then categorized based upon locus of control: (1) child-controlled (free-play), (2) shared-control (guided play), and (3) teacher-controlled (teacher-directed play and direct instruction). Following this deductive analysis that identified patterns related to play and direct instruction theory, three classroom pedagogical orientations emerged that reflected the prevalence of child, shared, or teacher-controlled pedagogies. Pedagogical orientation one displayed exclusively child-controlled pedagogy (i.e., free play), pedagogical orientation two displayed shared-controlled pedagogies (including either exclusively guided play, or a combination of free, guided, teacher directed play, and/or direct instruction), and pedagogical orientation three displayed exclusively teacher-controlled pedagogies (including 
teacher-directed play and/or direct instruction). In one classroom, there were no recorded observations of math, and therefore was excluded from the analysis. Two researchers analyzed the observations, engaging in inter-rater coding with a high degree of reliability. In instances of differently coded data, researchers discussed the codes until consensus was reached.

\section{Math Pedagogies}

The data revealed four distinct pedagogies (i.e., free play, guided play, teacher-directed play, and direct instruction), which were classified into two categories: play and direct instruction. Observational data across the 20 classrooms yielded 160 incidences of math learning. Of those 160 incidences, 113 (71\%) were of play ( $8 \%$ free play, 24\% guided, 39\% teacherdirected) and 47 (29\%) were of direct instruction, indicating that educators primarily used play as the learning context to support mathematics learning.

\section{Types of Play}

This paper ascribes to the conceptualization of play as a continuum, ranging from child, to mutually, to teacher-directed play (Pyle \& Danniels, 2017). The play observed in this study reflects this continuum, as the locus of control varied across incidences of play. Accordingly, three types of play were observed to support math development across the 20 classrooms: (1) free play, (2) guided play, and (3) teacher directed play.

Free play. Though free play was observed in all classrooms, minimal evidence of math learning was present in this type of play. Math learning only occurred in 13 incidences of free play and consisted of $8 \%$ of the observed math incidences, making it the least frequently observed play context for math learning. Free play, which was entirely controlled by the child as they practiced and explored mathematical ideas through their spontaneous choice of activity, occasionally allowed children to practice skills they acquired from previous experiences. For 
example, in Classroom 2, a child was observed stacking figurines in a pattern. Prior to the episode of free play, this child was engaged in guided play with her teacher, who modeled and explained how to create a repeating $\mathrm{AB}$ pattern by placing beads on a grid. Interestingly, the child had increased the complexity of her repeating pattern from the guided play scenario, where she made an $\mathrm{AB}$ pattern, to the free play scenario, where she constructed an $\mathrm{ABCD}$ pattern. This instance of free play provided the opportunity for this child to internalize and extend on a previously learned mathematical skill, though this was not a common occurrence.

Guided play. While guided play was observed in many classrooms, only some evidence of math learning occurred in this type of play. Math learning occurred in 38 incidences of guided play and consisted of $24 \%$ of the observed math incidences. Guided play was a collaborative experience between the teacher and child, as control over the play was shared between each member. However, the extent to which each participant controlled the play varied, as guided play ranged from more child-directed to more teacher-directed play. Regardless of who was exhibiting primary control, an adult was always involved in guided play and influenced the direction and outcome of the play scenario. For example, Class 6 demonstrated guided play that was more child-directed, when the children turned a constructive play center into an airport. As one child was building a car garage for the airport, the teacher joined the play and asked the child how travellers would be able to find their cars, suggesting the addition of numerals:

Child: [Teacher's name] come and look! I made some car parkings.

Teacher: Do you know what car spots have on them? ... Numbers. That helps people remember where they parked... Do you think for now you could put numbers in here? Do you want me to get you the number chart?

Child: Yes.

This play scenario originated from the children, the teacher then inserted mathematic learning goals (i.e., writing numerals), thereby extending the play to cover additional learning objectives. 
Guided play was also more teacher-directed in nature. For instance, children in Class 13 were learning about addition, through a contextualized problem-solving activity using inchimals (measuring blocks that ranged from 1- 12 inches, each size related to a specific animal i.e., the one-inch block was a lady bug, while the 12-inch block was a giraffe). The teacher presented children with a larger inchimal (e.g. an eight-inch snake) and asked children to find a combination of smaller inchimals that would be of equal size.

Teacher: How can you make it eight? Is eight the same as six? What can I put on top of the six to make them the same?

Child: One!

Teacher: Are six and one the same as eight?

Child: [places one-inch block on top of the six-inch block] Nooo.

Teacher: "Nope. Alright. Let's try another one"

Child: [places a two-inch block on top of the six-inch block] Two!

T: Two! Are six and two the same as eight?

Child: Yes.

One child discovered that when a tiger (six inches) and a frog (two inches) were combined, they were equal to the size of the snake (eight inches). In this example of guided play, the teacher set up the environment and gave children a task to complete, yet how the children completed the task was determined by them. Throughout the task, the teacher drew children's attention to key experiences that highlighted fundamental concepts of addition: numbers combine to make bigger numbers and different combination of numbers can equal the same answer.

Teacher-directed play. Teacher-directed play was the most frequently observed type of play in which math learning occurred, as 62 incidences of teacher-directed play were observed to support mathematics, which account for $39 \%$ of math observations. In teacher-directed play, the context was exclusively controlled by the teacher, with play scenarios that had predetermined outcomes and a directed process. For example, the teacher in Classroom 13 created a board game to support children's addition, number recognition, and counting skills. The purpose of this board 
game was to move cars to their parking spot by answering addition sentences. Children worked together to draw a card with an addition sentence, answer the addition sentence, locate the corresponding numeral on the board, and then move their player piece to the correct spot.

Teacher: What's that? [addition sentence on card] [Child tries to solve addition sentence, needs help]

Teacher: Let's see it...five plus five more... [models counting]... how many? Child: 10 .

Teacher: Alright [child's name] drive in, can you find the number 10 ? Where's 10 ? [Child moves car to the number 10]

Teacher: Good spot! Ok, whose turn is it?

Children were learning mathematical concepts in a playful manner yet were required to follow a discrete sequence of steps to complete the game properly. The teacher monitored the game to ensure students followed the correct steps and performed the appropriate mathematical operation to obtain the correct answer, providing support as required.

\section{Direct Instruction}

Math learning also occurred through direct instruction, which was observed in 47 of 160 math incidences (29\%). Direct instruction was a teacher-centric approach to learning that involved systematic and explicit modeling of a mathematical concept (Engelmann et al., 1981). For example, the morning routine in Classroom 9 involved answering a subtraction problem to determine how many children were at school.

Teacher: So, we have 30 [students] and how many students are away? Class: Two Teacher: Two, so if we take away two from 30, that would be one, and two [counts backwards from 30 on the 100 s chart] ... So, the number we are left now with is? Class: 28

Teacher: What's the answer boys and girls?

Class: 28 !

The teacher wrote the subtraction sentence on the board and modeled how to solve the problem by using a 100s chart, starting at 30 then counting back two numbers, to obtain the correct 
answer of 28 . This teacher explicitly modeled a concept, asked directed questions, and prompted desired responses, highlighting how knowledge transferred unilaterally from teacher to child.

\section{Classroom Pedagogical Orientations}

Free play, guided play, teacher-directed play, and direct instruction can be viewed or classified by locus of control. The observations of math learning were classified into three categories dependent upon who was controlling the learning context: (1) child-controlled; which included free-play, as free play is controlled entirely by the child, (2) shared-control, which included guided play, as guided play is a collaborative experience between teacher and child, (3) teacher-controlled, which included both teacher-directed play and direct instruction. Teacherdirected play and direct instruction do not differ substantially, as both involve a learning context that is controlled by the teacher (Weisberg et al., 2013). When classifying the observations of math learning by locus of control, rather than type of pedagogy, data showed the majority of observed math incidences were teacher-controlled ( $68 \%$ of math observations), followed by shared-control (24\% of math observations), with child-controlled incidences occurring the least often ( $8 \%$ of math observations). Based upon this classification, three classroom pedagogical orientations emerged from the data: classrooms that exclusively used child-controlled incidences to support math learning, classrooms where teachers and children shared control of the learning context, and classrooms that exclusively employed teacher-controlled learning contexts.

\section{Classroom Pedagogical Orientation One: Child-Controlled}

In three out of 20 classrooms, child-controlled learning contexts (i.e. free play), were exclusively used to support math development. A main strength observed in this pedagogical orientation was that free play provided the opportunity for children to practice and internalize mathematical skills and ideas. For example, the children in Class 20 classified and sorted found 
objects during outdoor play, thereby internalizing concepts of data management (Small, 2013). This type of practice is supported by Wallerstedt and Pramling (2012), who demonstrated that free play enables children to practice previously learned skills. Furthermore, a leading benefit to this pedagogical orientation is that children were afforded choice in their learning, which Weisberg et al. (2013) posited allowed children to direct their learning towards their interests, which in turn built self-efficacy.

Despite these benefits, free play did not support children's acquisition of new mathematical knowledge, limiting children's exposure to new concepts and restricting their ability to extend knowledge of existing concepts. For example, though the children in Class 20 practiced data organization skills by sorting objects, their learning neither extended their data management skills (e.g., representing the sorted objects in a chart or graph) nor acquired a new mathematical concept (e.g., addition). Additionally, instances of math were least frequently observed within child-controlled pedagogical orientation classrooms. The lack of opportunities for the extension of learning and the infrequency with which math was integrated in these classrooms aligns with previous research, which communicated the inefficacy of free play for math learning (e.g., Alfieri et al., 2011; Fisher et al., 2013).

\section{Classroom Pedagogical Orientation Two: Shared-Control}

In 10 out of 20 classrooms, control of mathematics learning contexts was shared between teacher and children. Shared control was observed in classrooms that exclusively used guided play, as well as classrooms that used a combination of free play, teacher directed play, and direct instruction. Regardless of the combination of pedagogies, there were opportunities for both children and teachers to control the learning context. For example, Teacher 7 used direct instruction to model how to use a t-chart to organize data. She also provided explicit instruction 
on how to use a referent object (in this case a wooden fish) to compare objects that are bigger and smaller than the referent. Children were then instructed to find items that were both bigger and smaller than the referent and record this data in a t-chart. During a subsequent episode of free play, a group of children was practicing this skill by comparing the wooden fish to the height of a garlic plant. One child noticed the garlic plant was shorter than the fish but had difficultly determining how much shorter it was.

Teacher: So it's a fraction of the fish. It's not the whole fish...So we're looking at this garlic... we're measuring how long it is. And we've decided it's not a whole fish long. Child: Maybe it's a quarter.

Teacher: [child's name] said this was half of a fish [points to half way point on fish], so it's more than half of a fish, but not a whole fish.

Child: A quarter.

Teacher: A quarter? A quarter of a fish would be down here [points to bottom quarter of fish]. So let's see...There's one quarter... there's two quarters.

Child: Three quarters!

Teacher: There's three quarters of a fish. [models how the height of a plant is three quarters of a fish]

This instance of free play became guided play when the teacher joined to model the degree to which objects can be bigger or smaller than a referent and introduced the idea of fractions.

This pedagogical orientation built upon and addressed the limitations of the childcontrolled pedagogical orientation, as children had choice within the learning context, yet the teacher also extended the learning and introduced new knowledge. Consider this example of the child practicing measuring objects during free play, a skill that was previously learned through direct instruction. While the free play was a good opportunity for this child to internalize mathematical concepts, the learning did not advance. However, when the teacher became involved, it became guided play, as the teacher directed the learning towards new mathematical concepts by viewing measurement and comparison as a ratio (i.e. the high of the plant was equal to the height of three quarters of a wooden fish). This finding corroborates previous research that 
emphasized the importance of adult involvement to extend knowledge and introduce novel information (Klahr, 2009).

Despite these strengths, classroom pedagogical orientation two was also not without challenges, the greatest being teacher availability. Current research highlights the importance of adult involvement to extend learning in play (Weisberg et al., 2013), however, with so many students in a classroom (up to 30 in the observed classrooms with only one to two educators) and limited time in the school day, teachers struggled to extend the learning of individual students. While the observed teachers who aligned with this pedagogical orientation strove to extend children's learning whenever possible, they did not have time to extend every child's learning, every day. This concern has been documented in the literature, as teachers who taught both large and small classes expressed the belief that class size impacted their teaching (Almulla, 2015).

\section{Classroom Pedagogical Orientation Three: Teacher-Controlled}

Six out of 20 classrooms exclusively used teacher-controlled pedagogies (i.e., a combination of teacher-directed play and direct instruction). For example, classroom 12 explicitly modelled counting strategies, such as grouping, doubles, and using an abacus with whole-class direct instruction. This instruction was followed by teacher-directed play in which children practiced a similar, yet distinct skill of composing numbers, as they were required to pull a number tile from a bin and then represent that number using a 10 frame. The play scenario helped to reinforce the concept acquired through direct instruction, yet the children did not have a choice in how the activity would transpire.

A prominent strength of this pedagogical orientation was that teachers could target and achieve specific curricular objectives in a playful manner. For example, Class 12, developed a specific curricular skill (compose and decompose quantities to 10; OME, 2016) by playfully 
representing numbers on a ten frame. Within the accountability context of public education, many teachers express pressure to obtain specific academic standards by the end of kindergarten (Stipek, 2017). Yet at the same time, express concern that this "push down" effect of academic pressure at an early age may diminish children's natural curiosity and motivation to learn (Stipek, 2017). However, Stipek (2017) asserts that examples of playful math instruction, as seen in Class 12, demonstrate that playful learning and the achievement of academic curricular objectives need not be dichotomized, as they can occur simultaneously.

While there are distinct advantages to the use of teacher-controlled learning environments, challenges remain, including a lack of child-choice. Within the playful learning example in Class 12, children were required to follow a specific sequence of steps that were prescribed by the teacher (i.e., draw a number tile from the bin and represent that number on your 10-frame). The absence of control could lead to negative impacts on student learning, such as decreased engagement, attention, and year-end student learning (Weisberg et al., 2013).

\section{Implications for Theory and Practice}

Research often supports guided play as an optimal pedagogy for facilitating math learning (e.g., Fisher et al., 2013). However, while several teachers in our study endorsed play as pedagogy, others used direct instruction methods more often. Furthermore, teacher-directed play, rather than guided play, was the most commonly observed context to support the teaching and learning of math, highlighting a potential misalignment between theory and practice.

\section{Pedagogical Barriers}

There are many possible reasons why guided play was not commonly observed in the classrooms. Primarily, the underrepresentation of guided play may be in response to the limitation outlined in classroom pedagogical orientation two; teacher availability. Guided play 
requires teacher involvement, which becomes increasingly difficult with larger class sizes. Almulla (2015) demonstrated that teachers of both large and small class sizes believe class size impacts their teaching practice, with teachers in larger classes reporting that they use a limited range of more teacher-centered pedagogies.

Secondly, teachers may face challenges when integrating novel practices into current pedagogy. Cohrssen, et al. (2016) argued that teaching practice is influenced by educators' experience and beliefs. Specifically, in regard to play-based learning, they suggested that educators may have been hesitant to implement this novel pedagogy, compared to more traditional direct instruction approaches, if they did not believe it to be in the best interest of children. In regard to mathematics education, they proposed that teachers' previous adverse experiences of math may have negatively impacted their current attitude and mathematics teaching practice. Despite these potential barriers, Cohrssen et al. (2016) demonstrated that supporting educators towards implementing play-based activities positively impacted their beliefs, which in turn positively impacted their practice.

Lastly, recent research demonstrates that teachers are uncertain of how to implement guided play in their classrooms (Pyle et al., 2018). Specifically, teachers expressed confusion on how to find a middle ground between free play and direct instruction, how to follow children's lead in play, and uncertainty surrounding optimal teacher involvement during play to support academic learning. These findings further highlight the difficulties teachers face when implementing novel practices in their classrooms. Therefore, rather than advocating for teachers to implement brand new practices, we propose supporting teachers by modeling how slight variations in current practice can bring guided play to the forefront.

\section{Overcoming Pedagogical Barriers}


To build upon what teachers are already successfully doing in their classrooms, we suggest that small adaptations can transform teacher-directed play into guided play to realign theory with practice. Pyle and Danniels' (2017) play continuum provides multiple entry points for implementing play-based learning in the classroom and the conceptual basis to demonstrate how small changes to teacher-directed play can shift practice along this continuum to a more guided play approach.

The first minor modification to teacher-directed play is to provide children with choice. For example, consider the incidences of teacher-directed and guided play from Classroom 13. In these classrooms, children were learning about the concept of addition in both teacher-directed play (answering addition sentences as part of a board game), and guided play (using inchimals to find combinations of animals of the same height). While the activities differ, the mathematical concept and context are consistent. However, in the guided play context, children had choice as they were given a problem (along with the resources and support), yet it was up to the children to figure out how to solve the problem. This open-ended context provided children with the opportunity to determine multiple possible solutions to the same problem, which will allow for greater knowledge transfer in future problem-solving activities (Kapur, 2010). Conversely, in the teacher-directed play, children were required to follow a predetermined and discrete sequence of steps in order to play the board game properly. To modify this teacher-directed board game and provide the opportunity for guided play, the teacher and children could co-create the rules of the game. The board game could still focus on the concept of addition, as intended by the teacher, yet how the addition problems are solved could be determined by the children. For example, instead of having just one representation of the addition statement (i.e. a numeric expression, $5+$ $5=$ ?) each card could have multiple representations of this addition statement (i.e. using tallies, 
dots, pictures). Furthermore, children could be provided with various materials to solve the addition problem by using multiple strategies (e.g. number lines, ten frames, counters). Not only does this differentiate the task, it also provides choice in how the problem is solved while simultaneously highlighting that there are numerous ways to conceptualize addition.

The second minor modification teachers can make to transform teacher-directed play into guided play is to use open-ended questioning. For example, when Teacher 13 was facilitating the board game, she used closed-ended questions and directives (e.g. "Five plus five more...10, alright, [child's name] ... can you find the number10? Where's 10?"). Whereas when she was facilitating the guided play incidence, she asked more open-ended questions (e.g. "How can you make it eight? Is eight the same as six? What can I put on top of the six to make them the same?"). Giving directives, or closed-ended statements, limits how children respond to play. Their actions become bound to the teacher's instructions, rather than a reflection of their own decision-making. Posing open-ended questions removes these limitations and can change how children respond to a play scenario, by offering them more choice within the context and thereby shifting teacher-directed play to guided play. Additionally, open-ended questions provide opportunities for children to show their learning in multiple ways, highlighting how teachers can support different approaches to problem solving rather than simply endorsing one specific answer. This provides children with more flexibility and creativity, which can be transferred to future problem-solving (Kapur, 2010).

These modifications to teacher-directed play respond to the potential pedagogical barriers in three fundamental ways. Primarily, these modifications address the teacher-availability challenges of guided play as child choice in a learning context does not have to equal teacher presence. Teachers can set up an activity, provide children with choice of how to complete the 
activity, then walk away. While children are engaged in this activity, the teacher is free to monitor and engage in other children's play, before returning to monitor progress and extend the learning. Secondly, these minor modifications address the potential challenges of implementing a novel pedagogy as they do not involve drastic changes to current practice. Instead, these suggestions build upon what teachers are already successfully doing in their classrooms. Thus, rather than viewing these modifications as novel pedagogy, they can be viewed as modified pedagogy. Lastly, these minor modifications begin to address the third potential barrier of teacher's uncertainty towards implementing guided play.

While this study begins to paint a picture of the current landscape of mathematics pedagogy in kindergarten classrooms, this picture is incomplete. Further research is needed to understand barriers teachers face in the implementation of guided play, how to help teachers overcome these barriers, as well as the extent to which guided play leads to math achievement in classrooms. While the existing research points to the benefits of guided play as a pedagogical tool for teaching mathematics, and our recommendations align with this current research, the possibility remains that guided play may not, in fact, be the best pedagogy to support mathematics in classroom settings. To build on the findings of experimental research, we now need classroom-based research that explores the mathematics outcomes of students in classrooms with different pedagogical orientations, including the use of guided play.

\section{Conclusions}

There is movement to improve mathematics education in kindergarten. In response, this study aimed to build upon theoretical and experimental studies that propose guided play as an optimal pedagogy for supporting early math learning, by observing the extent to which this research has transferred to classrooms. Results showed that while play was the primary context 
in which math was observed, the majority of observed math incidences occurred during teacherdirected play rather than guided play, suggesting that work is still needed to support the integration of guided play in complex kindergarten environments. Further research is needed to address this misalignment between theory and practice and explore methods to join these realms in an effort to improve early years mathematics education and the future of young learners.

\section{References}

Alfieri, L., Brooks, P. J., Aldrich, N. J., \& Tenenbaum, H. R. (2011). Does discovery-based instruction enhance learning? Journal of Educational Psychology, 103, 1-18. doi:10.1037/a0021017

Almulla, M. A. (2015). An investigation of teachers' perceptions of the effects of class size on teaching. International Education Studies, 8(12), 33-42. doi:10.5539/ies.v8n12p33

Bonawitz, E., Shafto, P., Gweon, H., Goodman, N. D., Spelke, E., \& Schulz, L. (2011). The double-edged sword of pedagogy: Instruction limits spontaneous exploration and discovery. Cognition, 120, 322-330. doi:10.1016/j.cognition.2010.10.001

Cohrssen, C., Church, A., \& Tayler, C. (2016). Play-based mathematics activities as a resource for changing educator attitudes and practice. SAGE Open, 6(2), 1-14. doi: $10.1177 / 2158244016649010$

Doabler, C. T., \& Fien, H. (2013). Explicit mathematics instruction: What teachers can do for teaching students with mathematics difficulties. Intervention in School and Clinic, 48(5), 276-285. doi:10.1177/1053451212473151

Duncan F. J., Dowsett, C. J., Claessent, A., Magnuson, K., Huston, A. C., Klebanove, P., ... Japel, C. (2007). School readiness and later achievement. Developmental Psychology, 43(6), 1428-1446. doi:10.1037/0012-1649.43.6.1428

Engelmann, S., Becker, W. C., Carnine, D., \& Rhine, R. (1981). The Direct Instruction Model. 
Encouraging Change in America's Schools: A Decade of Experimentation. New York, NY: Academic Press.

Fisher, K. R., Hirsh-Pasek, K., Newcombe, N., \& Golinkoff, R. M. (2013). Taking shape: Supporting preschoolers' acquisition of geometric knowledge though guided play. Child Development, 84(6), 1872-1878. doi: 10.1111/cdev.12091

Ginsburg, H. (2006). Playful mathematics and mathematical play: A guide for early education. In D. G. Singer, R.M. Golinkoff, \& K Hirsh-Pasek (Eds.), Play = Learning: How Play Motivates and Enhances Children's Cognitive and Social-Emotional Growth (pp.145168). Oxford University Press.

Gmitrová, V., Podhajecká, M., \& Gmitrov, J. (2009). Children’s play preferences: Implications for the preschool education. Early Child Development and Care, 179(3), 339-351. doi: $10.1080 / 03004430601101883$

Gopnik, A. (2012). Scientific thinking in young children: Theoretical advances, empirical research, and policy implications. Science, 337(6102), 1623-1627. doi:10.1126/science. 1223416

Griffin, S. (2004). Number worlds: A research-based mathematics program for young children. In Engaging Young Children in Mathematics: Standards for Early Childhood Mathematics Education, ed. Douglas H. Clements, Julie Sarama, and Ann-Marie DiBiase, 325-42.

Hart, C. H., Burts, D. C., Durland, M. A., Charlesworth, R., DeWolf, M., \& Fleege, P. O. (1998). Stress behaviors and activity type participation of preschoolers in more and less developmentally appropriate classrooms: SES and sex differences. Journal of Research in Childhood Education, 12, 176-196.

Kamii, K., \& Housman, L. B. (2000). Young children reinvent arithmetic: Implications of 
Piaget's theory (2nd ed.). New York, NY: Teacher's College Press.

Kapur, M. (2010). Productive failure in mathematical problem solving. Instructional Science, 38, 523-550. doi: 10.1007/s11251-009-9093-x

Klahr, D. (2009). "To everything there is a season, and a time to every purpose under the heavens": What about direct instruction? In S. Tobias \& T. M. Duffy (Eds.), Constructivist Theory Applied to Instruction: Success or Failure? (pp. 291-310). New York, NY: Taylor \& Francis.

Ontario Ministry of Education. (2016). The Kindergarten Program. Toronto, ON: Queen's Printer for Ontario.

Patton, M. Q. (2014). Qualitative Research and Evaluation Methods (4 ${ }^{\text {th }}$ ed.). London, UK: Sage.

Presser, A. L., Ginsburg, H., \& Ertle, B. (2015). Big math for little kids: The effectiveness of a preschool and kindergarten mathematics curriculum. Early Education and Development, 26, 399-426.

Pyle, A., \& Danniels, E. (2017). A continuum of play-based learning: The role of the teacher in play-based pedagogy and the fear of hijacking play. Early Education and Development, 28(3), 274-289. doi:10.1080/10409289.2016.1220771

Pyle, A., Poliszczuk, D., Danniels, E. (2018). The challenges of promoting literacy integration within a play-based learning kindergarten program: Teacher perspectives and implementation. Journal of Research in Childhood Education, 32(2) 219-233. doi: $10.1080 / 02568543.2017 .1416006$

Samara, J., \& Clements, D. H. (2009). Building blocks and cognitive building blocks. Playing to know the world mathematically. American Journal of Play, 1, 213-337. 
Small, M. (2013). Making Math Meaningful. US: Nelson.

Stipek, D. (2017). Playful math instruction in the context of standards and accountability. YC: Young Children, 72(3), 8-12.

Stokke, A. (2015). What to do About Canada's Declining Math Scores. Commentary No. 427. Toronto ON: C. D. Howe Institute. Retrieved from https://www.cdhowe.org/sites/default/files/attachments/research_papers/mixed/commenta ry_427.pdf

Tal, C., Fares, E., Azmi, R., \& Wabb, W. (2008). Beyond learning and teaching in preschool free-play centers in Daliat el-Carmel-Isfiya. Early Childhood Education Journal, 36, 281-289. doi:10.1007/s10643-008-0285-9

Turnbull, J., \& Jenvey, V. B. (2006). Criteria used by adults and children to categorize subtypes of play. Early Child Development and Care, 176(5), 539-551. doi: $10.1080 / 03004430500258172$

Wallerstedt, C., \& Pramling, N. (2012). Learning to play in a goal-directed practice. Early Years: An International Research Journal, 32(1), 5-15. doi: $10.1080 / 09575146.2011 .593028$

Weisberg, D. S., Hirsh-Pasek, K., Golinkoff, R. M. (2013). Guided play: Where curricular goals meet a playful pedagogy. Mind, Brain \& Education, 7(2), 104-112. https:/doi.org/10.1111/mbe.12015 